\title{
Optical Clearing of the Gastric Mucosa Using 40\%-glucose Solution
}

\author{
Vadim D. Genin ${ }^{1,2}$, Elina A. Genina ${ }^{1,2}$, Sergey V. Kapralov ${ }^{3}$, Veniamin A. Grishaev4, \\ Valery V. Tuchin ${ }^{1,2,5}$, Ekaterina N. Lazareva ${ }^{1,2}$, and Alexey N. Bashkatov ${ }^{1,2}$ \\ ${ }^{1}$ Saratov State University, 83 Astrakhanskaya Str., Saratov 410012, Russia \\ ${ }^{2}$ Tomsk State University, 36 Prosp. Lenina, Tomsk 634050, Russia \\ ${ }^{3}$ Engels City Clinical Hospital No. 1, 6 Vesennyaya Str., Engels, Saratov Region 413116, Russia \\ ${ }^{4}$ Saratov City Clinical Hospital No. 6 named after Acad. Koshelev, 15 Gvardeyskaya Str., Saratov 410033, Russia \\ ${ }^{5}$ Laboratory of Laser Diagnostics of Technical and Living Systems, Institute of Precision Mechanics and Control, \\ Russian Academy of Sciences, 24 Rabochaya Str., Saratov 410028, Russia \\ * e-mail: versetty2005@yandex.ru
}

\begin{abstract}
The kinetics of collimated transmittance of the gastric mucosa under the action of an aqueous 40\%-glucose solution was experimentally investigated. Based on the analysis of the transmittance kinetics, the value of the effective diffusion coefficient of glucose in the gastric mucosa was estimated and amounted to $(1.59 \pm 0.96) \times 10^{-6} \mathrm{~cm}^{2} / \mathrm{s}$. The permeability coefficient of the mucosa for glucose, calculated using the first Fick diffusion law, was estimated as $(2.81 \pm 0.90) \times 10^{-5} \mathrm{~cm} / \mathrm{s}$. It was shown that the introduction of the glucose solution into the mucosa reduced the light scattering coefficient by approximately 5-10\%. The increase in the depth of light penetration was from $5 \%$ to $15 \%$, depending on the selected spectral range. The results can be used to develop new methods of diagnosis and treatment of stomach diseases. (C) 2019 Journal of Biomedical Photonics \& Engineering.
\end{abstract}

Keywords: glucose; diffusion coefficient; permeability coefficient; light penetration depth; gastric mucosa; optical clearing.

Paper \#3327 received 16 Jul 2019; revised manuscript received 14 Sep 2019; accepted for publication 21 Sep 2019; published online 30 Sep 2019. doi: 10.18287/JBPE19.05.030302.

\section{Introduction}

Currently, non-invasive optical methods for diagnostics and therapy of various diseases are widely used in medicine, due to their safety for the health of patients and low cost [1-7]. At the same time, one of the main problems in their application is related to the delivery of probe radiation through the surface of biological tissue to the required depth. The complexity of this problem solving is associated with the limitations imposed by the scattering ability of biological tissues, which is the cause of the decrease in spatial resolution and depth of probing in the visible and near-infrared (NIR) spectral ranges [3]. It is well known that the optical radiation scattering in tissues is mainly connected with the mismatch of refractive indices of the tissue structural components (e.g. collagen and elastin fibers) and the interstitial fluid, as well as between cellular organelles and cytoplasm [3]. As shown in numerous studies (see, for example, Refs. [8-15]), the scattering properties of biological tissues can be effectively controlled by action of hyperosmotic immersion optical clearing agents (OCAs), which cause diffusion of water from interstitial space and partially replace the interstitial fluid. This method is known in literature as a "tissue optical clearing" technique. The introduction of an OCA with a higher refractive index than an interstitial fluid into tissue leads to matching the refractive indices of the scatterers and the interstitial fluid, which significantly reduces light scattering in the biological tissue. The described method of the control of tissue optical characteristics is important both for studying fundamental laws of tissue metabolism and for development of the optical and laser methods of diagnostics, therapy and surgery. 
Among substances used as OCAs, a special place is occupied by aqueous solutions of glucose of various concentrations due to their biocompatibility and low cost [8-20]. Most often, glucose solutions are used for the optical clearing of connective tissues, such as skin dermis, sclera, dura mater, etc. In addition, the optical clearing of blood in the presence of glucose contributes to development of methods for blood glucose monitoring $[11,12,20,21]$.

At the same time, despite such numerous studies, the optical clearing of gastrointestinal tract mucosa has been studied not enough. It has been shown that the use of OCAs, such as glycerol and dimethyl sulfoxide (DMSO) solutions, contributes to effective optical clearing of the stomach tissues in the NIR spectral region [22-25]. At this the use of aqueous glucose solutions is not sufficiently studied, although some investigations have suggested differentiation of normal and tumor tissues of the stomach, colon and esophagus based on the difference in their permeability to aqueous solutions of glucose [16, 26-28]. It should be noted that despite a number of works aimed at measuring the tissue permeability coefficients for aqueous glucose solutions [16, 26-28], we could not find a single work devoted to the measuring of the glucose diffusion coefficient in the gastric mucosa.

It is obvious that the knowledge of the diffusion coefficients of OCAs in biological tissues is necessary for the development and optimization of tissue optical clearing technique. Therefore, the purpose of this work is to study the temporal dependence of collimated transmittance of the gastric mucosa under the action of the aqueous $40 \%$-glucose solution and evaluate on this basis the effectiveness of tissue optical clearing as well as the glucose diffusion coefficient in the mucosa.

\section{Materials and Methods}

The study was performed with 10 samples of the human gastric mucosa, from different patients obtained in the course of planned operations or anatomical investigations. The experimental studies were approved by the Ethics Committee of V.I. Razumovsky Saratov State Medical University. Immediately after autopsy, tissue samples were placed in a $0.9 \% \mathrm{NaCl}$ solution and were kept in it until spectral measurements for 4-8 h at $\sim 4{ }^{\circ} \mathrm{C}$. The area of the samples was approximately $1.5 \times 1 \mathrm{~cm}^{2}$, the average thickness measured with an electronic micrometer varied from $0.36 \pm 0.10$ to $0.70 \pm 0.20 \mathrm{~mm}$.

The spectra of collimated transmittance of the gastric mucosa were measured using a multichannel USB4000-Vis-NIR spectrometer (Ocean Optics, USA) in the spectral range of 400-1000 $\mathrm{nm}$. The tissue sample was fixed on a plastic plate (size $\left.3.5 \times 1.5 \mathrm{~cm}^{2}\right)$ with a rectangular hole in the center (size $8 \times 8 \mathrm{~mm}^{2}$ ) and placed in a $5 \mathrm{~mL}$ glass cuvette with glucose solution. The cuvette was placed between two QP400-1-VIS-NIR optical fibers (Ocean Optics, USA) with $400 \mu \mathrm{m}$ core diameter. To provide the beam collimation, the collimators 74-ACR (Ocean Optics, USA) were fixed at the ends of the fibers, using standard SMA-905 connectors. Halogen lamp HL-2000 (Ocean Optics, USA) was used as a light source. The spectra of collimated transmittance were recorded every 1-2 min for $30 \mathrm{~min}$ after placing the mucosa sample into glucose solution. The measurement error did not exceed $5 \%$ of the measured value in the wavelength range above $500 \mathrm{~nm}$ and $10 \%$ in the shorter wavelength region of the spectrum. The measurement error (the standard deviation) included collimation error, instrumental error, light source fluctuations, etc., and tissue optical properties variability. For assessment of the error, the collimated transmittance spectrum of the thickest tissue sample (with thickness of $0.70 \pm 0.20 \mathrm{~mm}$ ) was measured in empty cuvette, without optical clearing agent, ten times. At that the tissue sample was taken out and put into cuvette again to take into account the variability of the tissue optical properties in different part of the sample. After that the mean and the standard deviation were calculated for each wavelength. All measurements were carried out at room temperature $\sim 20^{\circ} \mathrm{C}$.

Commercially available aqueous $40 \%$-glucose solution for injection (Dalchempharm, Russia) was used as an OCA. The $\mathrm{pH}$ of this solution was measured using $\mathrm{pH}$-meter (Hanna, Germany) as 3.5. The refractive index of the solution was measured with a multiwavelength refractometer Abbe DR-M2/1550 (ATAGO, Japan) at 12 wavelengths in the spectral range of 480-1550 nm with precision of 0.0002 and the measurement results are presented in Table 1.

Interpolation was performed using the Sellmeier dispersion formula [29], presented in the form:

$$
n(\lambda)=\sqrt{\frac{2 P(\lambda)+1}{1-P(\lambda)}},
$$

where $P(\lambda)=a_{0}+a_{1} \lambda^{* 2}+\frac{a_{2}}{\lambda^{* 2}}+\frac{a_{3}}{\lambda^{* 2}-\lambda_{U V}^{2}}+\frac{a_{4}}{\lambda^{* 2}-\lambda_{I R}^{2}}$; $n$ is the refractive index of an aqueous solution of glucose; $\lambda^{*}=\lambda / \lambda_{0}$ is the relative wavelength, $\lambda_{0}=589 \mathrm{~nm} ; \lambda_{U V}=229.202 \mathrm{~nm} ; \lambda_{I R}=5432.937 \mathrm{~nm} ; \lambda$ is the wavelength in $\mathrm{nm}$. The interpolation coefficients $\left(a_{0}\right.$, $a_{1}, a_{2}, a_{3}, a_{4}$ ) are shown in Table 2 .

In the study of the interaction between the glucose solution and samples of the mucosa, it was assumed that only the refractive index of the interstitial fluid is changed due to glucose diffusion into the sample and osmotic outflow of water from the tissue. In this case, the refractive indices of the scatterers and the interstitial fluid were matched, which led to a decrease in the scattering coefficient of the tissue. The study of the kinetics of this process allows for estimation of the diffusion coefficient as a measure of the mean exchange flow rate of glucose molecules into the tissue [30]. This means that for the treatments of mucosa with $40 \%$ glucose solution, in particular, glucose diffuses into the 
Table 1 The refractive indices of the aqueous 40\%-glucose solution, measured at different wavelengths

\begin{tabular}{ccccccccccccc}
\hline$\lambda, \mathrm{nm}$ & 480 & 486 & 546 & 589 & 644 & 656 & 680 & 800 & 930 & 1100 & 1300 & 1550 \\
\hline$n$ & 1.3957 & 1.3959 & 1.3925 & 1.391 & 1.3891 & 1.3886 & 1.3877 & 1.3846 & 1.3813 & 1.378 & 1.3748 & 1.371 \\
\hline
\end{tabular}

Table 2 The interpolation coefficients of the spectral dependence of the refractive index of the aqueous $40 \%$-glucose solution

\begin{tabular}{ccccc}
\hline$a_{0}$ & $a_{1}$ & $a_{2}$ & $a_{3}$ & $a_{4}$ \\
\hline 0.27094 & $-1.0746 \times 10^{-3}$ & $5.34504 \times 10^{-3}$ & 991.71185 & $5.5939 \times 10^{5}$ \\
\hline
\end{tabular}

tissues during all the treatment due to equilibrium between the water in the immersing solution and the water inside the tissue. The water flow is insignificant and the coefficients of permeability and diffusion are determined only by the slower diffusion of glucose molecules [28].

The process of glucose transport in the gastric mucosa was described in the framework of the free diffusion model. The following assumptions were made regarding the transfer process: 1) only concentration diffusion takes place, i.e. the exchange flux of glucose into biological tissue and water from the tissue at this point is proportional to the gradient of glucose concentration at this point; 2) the diffusion coefficient is constant at all points inside the sample of biological tissue. The solution of the diffusion equation, described in detail in Ref. [30], made it possible to estimate the average concentration of glucose solution inside the sample at each time point.

In the first approximation, solution of the second Fick diffusion law equation has the form [30]:

$$
C(t)=C_{0}\left(1-\exp \left(-\frac{t}{\tau}\right)\right)
$$

where $C(t)$ is the volume-averaged concentration of OCA inside the sample; $C_{0}$ is the concentration of glucose in the immersion solution; $t$ is the time, sec; $\tau=\frac{l^{2}}{\pi^{2} D}$ is the characteristic diffusion time, sec; $l$ is the thickness of the sample of mucosa, cm; $D$ is the diffusion coefficient, $\mathrm{cm}^{2} / \mathrm{s}$.

As it was shown earlier [17, 28, 31-34], the dependence of the collimated transmittance $T_{c}$ of a tissue sample placed in an immersion liquid, over time, for each wavelength, can be represented as:

$$
T_{c}(t) \approx \frac{C(t)}{C_{0}}=1-\exp \left(-\frac{t}{\tau}\right)
$$

Measurement of the characteristic diffusion time $\tau$ was carried out using the least squares method:

$$
\tau=-\frac{\sum_{j=1}^{N} t_{j}^{2}}{\sum_{j=1}^{N}\left(t_{j} \ln y_{j}\right)}
$$

where $t_{j}$ is the moment of measurement of each value $T_{c}$, $y=1-T_{c} / A ; A$ is the maximum value of the collimated transmittance, $N$ is the total number of experimental points obtained by registering the kinetics of collimated transmittance at a fixed wavelength. Accordingly, the diffusion coefficient $D$ was determined from the relationship:

$$
D=\frac{l^{2}}{\pi^{2} \tau}
$$

After determining of the value of $D$ from the analysis of the collimated transmittance kinetics, measured at each individual wavelength, the obtained values were averaged over all wavelengths of the measured spectral range.

Knowledge of the value of $D$ allowed us to determine the permeability coefficient $(P)$ of the biological tissue under study for a diffusing substance, associated with the value of the diffusion coefficient by the expression [35]:

$$
P=\frac{D}{l}
$$

The optical clearing efficiency (OCE) is one of the most important parameters, allowing to evaluate the effectiveness of the use of those or other clearing agents and to compare them with each other. Quantitatively, the efficiency of optical clearing is determined by the expression [17, 31, 36-38]:

$$
\mathrm{OCE}=\frac{\mu_{t}(t=0)-\mu_{t}^{\min }}{\mu_{t}(t=0)},
$$

where $\mu_{t}=-\ln \left(T_{c}\right) / l$ is the attenuation coefficient, $1 / \mathrm{cm} ; \mu_{t}^{\min }$ is the minimal value of the attenuation 
coefficient measured during the optical clearing process, $1 / \mathrm{cm}$. In the framework of this work, the OCE values were determined for each wavelength in each of the three selected spectral ranges (500-600 nm, $600-700 \mathrm{~nm}$ and $700-900 \mathrm{~nm})$, and then the obtained values were averaged.

Another important characteristic for correct determination of the radiation dose in the course of photochemical and photodynamic therapy of various diseases, as well as the dosimetry of optical radiation at laser surgery of a stomach ulcer is the depth of light penetration. In diffusion approximation, the assessment of the depth of light penetration into biological tissue $(\delta)$ is performed using the expression: $\delta=1 / \sqrt{3 \mu_{a}\left(\mu_{a}+\mu_{s}^{\prime}\right)}$ [1]. This expression is true when a "pencil" beam is incident on the surface of the scattering medium, and the diffuse radiant fluence mainly is created by diffusely scattered photons. We have previously shown [39] that the maximum effect is observed in the spectral region of 700-900 nm, where the depth of light penetration approximately corresponds to the total thickness of the gastric mucosa/submucosa and muscle layer and amounts more than $3 \mathrm{~mm}$, which indicates a sufficiently large amount of radiation penetrating into the abdominal cavity. In the spectral range above $900 \mathrm{~nm}$ with increasing wavelength, the depth of light penetration significantly decreases to $0.6 \mathrm{~mm}$ in the region of the water absorption band with a maximum on $1940 \mathrm{~nm}$. Analysis of the penetration depth of ballistic photons used for imaging in OCT or confocal microscopy can be performed on the basis of the expression [40]:

$$
\delta_{c}=1 / \mu_{t}
$$

The values $\delta_{c}$ were determined for each wavelength in each of the three selected spectral ranges (500-600 nm, 600-700 nm, and 700-900 nm), and then the resulting values were averaged. The change in the depth of penetration of ballistic photons was estimated using the expression:

$$
\Delta \delta_{c}=\frac{\delta_{c}^{\max }-\delta_{c}(t=0)}{\delta_{c}(t=0)}
$$

Here $\delta_{c}^{\max }$ is the maximal value of the light penetration depth measured during the optical clearing process, $1 / \mathrm{cm}$.

\section{Results and Discussion}

Figs. 1 and 2 present the typical spectral and temporal dependences of the collimated transmittance of the sample of gastric mucosa affected by the studied glucose solution. Fig. 1 shows that at the initial moment the sample of mucosa is not transparent to optical radiation. In the process of replacing water molecules in the interstitial fluid with glucose molecules, we have observed the increase in optical transmittance, i.e., the mucosa transparency, which is due to the matching of refractive indices of the interstitial fluid and the tissue scatterers. As a result, the scattering has been reduced and the collimated transmittance has been increased.

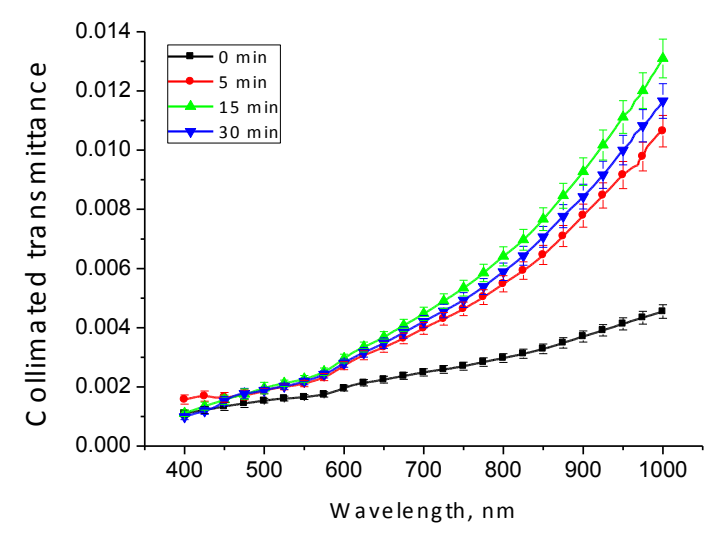

Fig. 1 Typical collimated transmittance spectra of gastric mucosa influenced by aqueous $40 \%$-glucose solution measured in different time intervals.

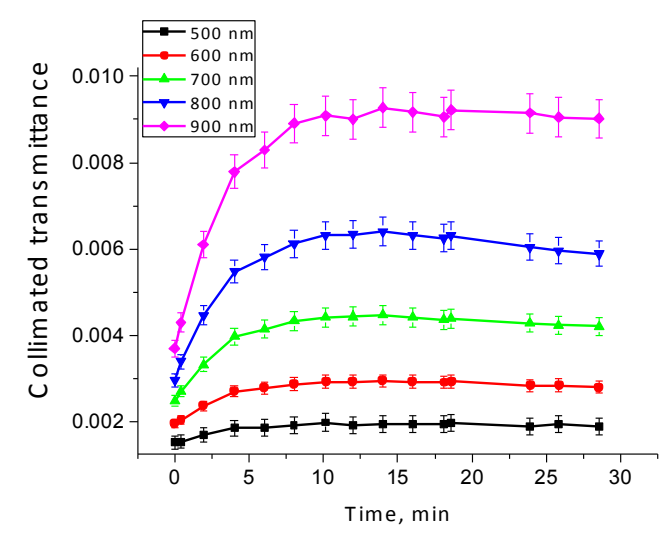

Fig. 2 Typical collimated transmittance kinetics of the gastric mucosa influenced by aqueous $40 \%$-glucose solution measured for different wavelengths.

From Fig. 2, it follows that the maximum clearing effect of the gastric mucosa under the action of the glucose solution is observed in the first $10 \mathrm{~min}$ after beginning the experiment, with the greatest effect being achieved in the NIR spectral range, where the collimated transmittance increases by about $2-2.5$ fold.

The analysis of the kinetics of collimated transmittance of the gastric mucosa samples with the above presented algorithm was used for estimation of the relative diffusion coefficient of $40 \%$-glucose solution in the tissue; and the value amounted to $(1.59 \pm 0.96) \times 10^{-6} \mathrm{~cm}^{2} / \mathrm{s}$. The corresponding value of permeability coefficient was estimated as $(2.81 \pm 0.90) \times 10^{-5} \mathrm{~cm} / \mathrm{s}$. The obtained values agree quite well with the data measured in the works [16, 26-28] and presented in Table 3. From the table, it follows that 
Table 3 The permeability coefficients $(P)$, diffusion coefficients $(D)$ and characteristic diffusion time $(\tau)$ of aqueous solutions of glucose in mucosa of digestive tract organs

\begin{tabular}{|c|c|c|c|c|}
\hline Tissue & $\begin{array}{c}\text { Concentration } \\
\text { of glucose }\end{array}$ & $P, \mathrm{~cm} / \mathrm{s}$ & $D, \mathrm{~cm}^{2} / \mathrm{s}$ & $\tau, \mathbf{s}$ \\
\hline $\begin{array}{l}\text { Mice stomach } \\
(l=330 \mu \mathrm{m})\end{array}$ & $20 \%$ & $(9.4 \pm 0.4) \times 10^{-6}[16]$ & $(3.1 \pm 0.1) \times 10^{-7} *$ & $817.6 \pm 26.4 * *$ \\
\hline $\begin{array}{l}\text { Normal human colon } \\
(l=391 \mu \mathrm{m})\end{array}$ & $30 \%$ & $(3.37 \pm 0.23) \times 10^{-6}[26]$ & $(1.318 \pm 0.090) \times 10^{-7} *$ & $1928.0 \pm 132.1^{* *}$ \\
\hline $\begin{array}{l}\text { Human normal esophagus } \\
(l=500 \mu \mathrm{m})\end{array}$ & $40 \%$ & $(1.74 \pm 0.04) \times 10^{-5}[27]$ & $(8.7 \pm 0.2) \times 10^{-7} *$ & $291.3 \pm 6.7^{* *}$ \\
\hline $\begin{array}{l}\text { Healthy colorectal mucosa } \\
(l=500 \mu \mathrm{m})\end{array}$ & $20 \%$ & $(7.782 \pm 0.024) \times 10^{-5} * * *$ & $(3.891 \pm 0.012) \times 10^{-6} * * * *$ & $65.1 \pm 0.2[28]$ \\
\hline $\begin{array}{l}\text { Healthy colorectal mucosa } \\
(l=500 \mu \mathrm{m})\end{array}$ & $25 \%$ & $(7.31 \pm 0.34) \times 10^{-5 * * *}$ & $(3.655 \pm 0.169) \times 10^{-6} * * * *$ & $69.4 \pm 3.2[28]$ \\
\hline $\begin{array}{l}\text { Healthy colorectal mucosa } \\
(l=500 \mu \mathrm{m})\end{array}$ & $30 \%$ & $(6.27 \pm 0.47) \times 10^{-5 * * *}$ & $(3.135 \pm 0.236) \times 10^{-6 * * * *}$ & $81.1 \pm 6.1[28]$ \\
\hline $\begin{array}{l}\text { Healthy colorectal mucosa } \\
(l=500 \mu \mathrm{m})\end{array}$ & $35 \%$ & $(3.66 \pm 0.16) \times 10^{-5 * * *}$ & $(1.83 \pm 0.08) \times 10^{-6} * * * *$ & $138.4 \pm 5.9[28]$ \\
\hline $\begin{array}{l}\text { Healthy colorectal mucosa } \\
(l=500 \mu \mathrm{m})\end{array}$ & $40 \%$ & $(1.693 \pm 0.027) \times 10^{-5 * * *}$ & $(8.467 \pm 0.133) \times 10^{-7 * * * *}$ & $299.2 \pm 4.7[28]$ \\
\hline $\begin{array}{l}\text { Healthy colorectal mucosa } \\
(l=500 \mu \mathrm{m})\end{array}$ & $45 \%$ & $(2.396 \pm 0.069) \times 10^{-5 * * *}$ & $(1.198 \pm 0.035) \times 10^{-6 * * * *}$ & $211.5 \pm 6.1[28]$ \\
\hline $\begin{array}{l}\text { Healthy colorectal mucosa } \\
(l=500 \mu \mathrm{m})\end{array}$ & $50 \%$ & $(4.858 \pm 0.061) \times 10^{-5} * * *$ & $(2.43 \pm 0.03) \times 10^{-6 * * * *}$ & $104.3 \pm 1.3[28]$ \\
\hline $\begin{array}{l}\text { Human gastric mucosa } \\
(l=530 \pm 240 \mu \mathrm{m})\end{array}$ & $40 \%$ & $\begin{array}{l}(2.81 \pm 0.90) \times 10^{-5} \\
{[\text { This work] }}\end{array}$ & $\begin{array}{l}(1.59 \pm 0.96) \times 10^{-6} \\
{[\text { This work] }}\end{array}$ & $\begin{array}{l}191.40 \pm 0.34 \\
{[\text { This work] }} \\
219.2 \pm 159.0 * *\end{array}$ \\
\hline $\begin{array}{l}* \text { the diffusion coefficient calc } \\
* * \text { the characteristic diffusion } \\
\tau=\frac{l^{2}}{\pi^{2} D} \text { for sample thickness }\end{array}$ & $\begin{array}{l}\text { tion was performe } \\
\text { e calculation was } \\
0 \mu \mathrm{m} \text {. }\end{array}$ & $\begin{array}{l}\text { using the expression } D= \\
\text { erformed using the expre }\end{array}$ & & \\
\hline
\end{tabular}

literature data for glucose diffusion coefficients in the digestive tract mucosa are in the range from $(1.318 \pm 0.090) \times 10^{-7} \mathrm{~cm}^{2} / \mathrm{s}$ [26] to $(3.891 \pm 0.012) \times 10^{-6}$ $\mathrm{cm}^{2} / \mathrm{s}$ [28]. Thus, the value obtained in this paper for glucose diffusion coefficient is in the range of values obtained by other researchers. The differences could be originated from different concentration of glucose solution used in the measurements, because, as it was shown in Refs. [28, 32-34], measured values significantly depend on glucose concentration, and also on $\mathrm{pH}$. Similarly, the permeability coefficient measured in this paper is also in the range of published data $(3.37 \pm 0.23) \times 10^{-6} \mathrm{~cm} / \mathrm{s} \quad[26]$ and $(7.782 \pm 0.024) \times 10^{-5}$ $\mathrm{cm} / \mathrm{s}[28]$.

Unfortunately, a direct comparison of the obtained values of the mass transport parameters (coefficients of diffusion and permeability) is rather difficult, due to the use of different measurement and experimental data processing methods, as well as different structural and morphological features of the studied tissues. So, for example, the authors of $[16,26,27]$ used optical coherence tomography signal slope analysis (OCTSS) [13] for measuring the permeability coefficient of the mucosa. The authors of Ref. [28] performed the measurement of glucose diffusion rate using transmission spectroscopy (like the authors of the presented work), but the results were presented in the form of characteristic diffusion times of glucose. To compare our data and data obtained by other researchers, we recalculated the values of permeability coefficients or characteristic diffusion times that they obtained, into the values of diffusion coefficients. The results are presented in Table 3.

Table 4 The efficiency of optical clearing (OCE), calculated using Eq. (6) and the depth of penetration of collimated radiation, calculated using Eqs. (7) and (8)

\begin{tabular}{c|c|c|c}
\hline & \multicolumn{3}{|c}{ Spectral range } \\
\cline { 2 - 4 } OCE & $500-600 \mathrm{~nm}$ & $600-700 \mathrm{~nm}$ & $700-900 \mathrm{~nm}$ \\
\hline$\delta_{c}(t=0), \mu \mathrm{m}$ & $83.0 \pm 0.8$ & $86.9 \pm 0.9$ & $91.2 \pm 1.8$ \\
\hline$\delta_{c}^{\max }$ & & & \\
$(t \approx 20 \mathrm{~min})$, & $87.4 \pm 1.6$ & $94.5 \pm 1.9$ & $104.8 \pm 4.4$ \\
$\mu \mathrm{m}$ & & & \\
\hline$\Delta \delta_{c}$ & $0.053 \pm 0.019$ & $0.088 \pm 0.021$ & $0.149 \pm 0.046$ \\
\hline
\end{tabular}


The results of measurements of the efficiency of optical clearing and the change in the depth of collimated radiation penetration in the three spectral ranges are presented in Table 4 . It is clearly seen that an aqueous solution of glucose significantly reduces light scattering in the gastric mucosa, thereby increases the penetration depth of probe radiation, which is crucial for planning and conducting diagnostic or therapeutic procedures, including laser surgery of a stomach ulcer.

To comparison the OCE of the investigated $40 \%$ glucose solution with other optical clearing agents (such as glycerol and DMSO solutions) we calculated relative increasing of stomach tissue transmittance as $\Delta T=\frac{T(t=30 \mathrm{~min})-T(t=0 \mathrm{~min})}{T(t=0 \mathrm{~min})} \times 100 \% \quad$ [25] in the spectral range $800-1000 \mathrm{~nm}$. In our experiments we obtained the $\Delta T \approx 26.3 \pm 0.14 \%$. In the work [22] it was found that light transmittance was increased by approximately $23 \%$ at $30 \mathrm{~min}$ after $80 \%$-glycerol solution, while $15 \%$ and $11 \%$ were obtained after the treatment of the tissue with $50 \%$-glycerol and $50 \%$ DMSO, respectively. It should be noted that the use of mixure of $50 \%$-glycerol solution with $30 \%$-DMSO solution for optical clearing increases the transmittance up to approximately $29 \%$ at 30 min after the application [25]. Thus, we can see that OCE of $40 \%$-glucose solution is comparable with OCE of glycerol and DMSO solutions used for stomach tissue optical clearing.

\section{Conclusion}

The paper presents results of measurement of the diffusion coefficient of glucose in the gastric mucosa in vitro. The measured value of the relative diffusion coefficient is $(1.59 \pm 0.96) \times 10^{-6} \mathrm{~cm}^{2} / \mathrm{s}$, which allows estimating the value of the mucosal permeability coefficient for glucose molecules as $(2.81 \pm 0.90) \times 10^{-5}$ $\mathrm{cm} / \mathrm{s}$. It is shown that the administration of an aqueous solution of glucose into the mucosa provides a decrease in the light scattering coefficient by approximately $5-10 \%$. The increase in the light penetration depth is from $5 \%$ to $15 \%$, depending on the selected spectral range.

The results obtained has allowed us to evaluate the effectiveness of using the aqueous $40 \%$-glucose solution as an optical clearing agent for controlling the optical characteristics of the gastric mucosa, and they can be used to develop new methods for diagnostics and treatment of stomach diseases.

\section{Disclosures}

All authors declare that there is no conflict of interests in this paper.

\section{Acknowledgement}

The study was supported by the RFBR grant No. 19-32-90224.

\section{References}

1. V. V. Tuchin, Tissue Optics: Light Scattering Methods and Instruments for Medical Diagnosis, 3rd Edition, SPIE Press, Bellingham, Washington (2015).

2. V. V. Tuchin (Ed.), Handbook of Optical Biomedical Diagnostics, 2nd Edition, SPIE Press, Bellingham, Washington (2016).

3. V. V. Tuchin, "Tissue optics and photonics: light-tissue interaction," Journal of Biomedical Photonics \& Engineering 1(2), 98-134 (2015).

4. A. J. Welch, M. J. C. van Gemert (Eds.), Optical-thermal response of laser-irradiated tissue, 2nd Edition, Springer (2011).

5. D. A. Boas, C. Pitris, and N. Ramanujan (Eds.), Handbook of Biomedical Optics, CRC Press, Taylor \& Francis Group (2011).

6. S. H. Yun, S. J. J. Kwok, "Light in diagnosis, therapy and surgery," Nature Biomedical Engineering 1(1), 0008 (2017).

7. A. Méndez, "Optics in Medicine," Chap. 13 in Optics in Our Time, M. Al-Amri, M. El-Gomati, and M. Zubairy (Eds.), Springer, 299-333 (2016).

8. I. Carneiro, S. Carvalho, V. Silva, R. Henrique, R. Oliveira, and V. V. Tuchin, "Kinetics of optical properties of human colorectal tissues during optical clearing: a comparative study between normal and pathological tissues," Journal of Biomedical Optics 23(12), 121620 (2018).

9. W. Feng, R. Shi, N. Ma, D. K. Tuchina, V. V. Tuchin, and D. Zhu, "Skin optical clearing potential of disaccharides," Journal of Biomedical Optics 21(8), 081207 (2016).

10. E. A. Genina, A. N. Bashkatov, and V. V. Tuchin, "Glucose-induced optical clearing effects in tissues and blood," Chap. 21 in Handbook of Optical Sensing of Glucose in Biological Fluids and Tissues, V. V. Tuchin (Ed.), Taylor \& Francis Group LLC, CRC Press, 657-692 (2009).

11. E. A. Genina, A. N. Bashkatov, and V. V. Tuchin, “Tissue optical immersion clearing," Expert Review of Medical Devices 7(6), 825-842 (2010). 
12. E. A. Genina, A. N. Bashkatov, Yu. P. Sinichkin, I. Yu. Yanina, and V. V. Tuchin, "Optical clearing of tissues: benefits for biology, medical diagnostics, and phototherapy," Chap. 10 in Handbook of Optical Biomedical Diagnostics, 2nd Edition, V. V. Tuchin (Ed.), SPIE Press, Bellingham, Washington, 565-637 (2016).

13. K. V. Larin, M. G. Ghosn, A. N. Bashkatov, E. A. Genina, N. A. Trunina, and V. V. Tuchin, "Optical clearing for OCT image enhancement and in-depth monitoring of molecular diffusion," IEEE Journal of Selected Topics in Quantum Electronics 18(3), 1244-1259 (2012).

14. J. Wang, N. Ma, R. Shi, Y. Zhang, T. Yu, and D. Zhu, "Sugar-induced skin optical clearing: from molecular dynamics simulation to experimental demonstration," IEEE Journal of Selected Topics in Quantum Electronics 20(2), 7101007 (2014).

15. D. Zhu, K. Larin, Q. Luo, and V. V. Tuchin, "Recent progress in tissue optical clearing," Laser \& Photonics Reviews 7(5), 732-757 (2013).

16. H. Xiong, Z. Guo, C. Zeng, L. Wang, Y. He, and S. Liu, "Application of hyperosmotic agent to determine gastric cancer with optical coherence tomography ex vivo in mice," Journal of Biomedical Optics 14(2), 024029 (2009).

17. D. K. Tuchina, R. Shi, A. N. Bashkatov, E. A. Genina, D. Zhu, Q. Luo, and V. V. Tuchin, "Ex vivo optical measurements of glucose diffusion kinetics in native and diabetic mouse skin," Journal of Biophotonics 8(4), 332$346(2015)$.

18. D. K. Tuchina, P. A. Timoshina, V. V. Tuchin, A. N. Bashkatov, and E. A. Genina, "Kinetics of rat skin optical clearing at topical application of 40\% glucose: ex vivo and in vivo studies," IEEE Journal of Selected Topics in Quantum Electronics 25(1), 7200508 (2019).

19. D. K. Tuchina, A. N. Bashkatov, E. A. Genina, and V. V. Tuchin, "Quantification of glucose and glycerol diffusion in myocardium,” Journal of Innovative Optical Health Sciences 8(3), 1541006 (2015).

20. H. Ullah, F. Hussain, and M. Ikram, "Optical coherence tomography for glucose monitoring in blood," Applied Physics B 120, 355-366 (2015).

21. R. V. Kuranov, V. V. Sapozhnikova, D. S. Prough, I. Cicenaite, and R. O. Esenaliev, "In vivo study of glucoseinduced changes in skin properties assessed with optical coherence tomography," Physics in Medicine \& Biology 51, 3885-3900 (2006).

22. R. K. Wang, X. Xu, Y. He, and J. B. Elder, "Investigation of optical clearing of gastric tissue immersed with hyperosmotic agents," IEEE Journal of Selected Topics in Quantum Electronics 9(2), 234-242 (2003).

23. X. Xu, R. Wang, and J. B. Elder, "Optical clearing effect on gastric tissues immersed with biocompatible chemical agents investigated by near infrared reflectance spectroscopy,” Journal of Physics D: Applied Physics 36, 17071713 (2003).

24. Y. He, R. K. Wang, "Dynamic optical clearing effect of tissue impregnated with hyperosmotic agents and studied with optical coherence tomography," Journal of Biomedical Optics 9(1), 200-206 (2004).

25. X. Xu, R. K. Wang, "Synergistic effect of hyperosmotic agents of dimethyl sulfoxide and glycerol on optical clearing of gastric tissue studied with near infrared spectroscopy," Physics in Medicine and Biology 49, 457-468 (2004).

26. Q. Zhao, C. Zhou, H. Wei, Y. He, X. Chai, and Q. Ren, "Ex vivo determination of glucose permeability and optical attenuation coefficient in normal and adenomatous human colon tissues using spectral domain optical coherence tomography," Journal of Biomedical Optics 17(10), 105004 (2012).

27. Q. L. Zhao, J. L. Si, Z. Y. Guo, H. J. Wei, H. Q. Yang, G. Y. Wu, S. S. Xie, X. Y. Li, X. Guo, H. Q. Zhong, and L. Q. Li, "Quantifying glucose permeability and enhanced light penetration in ex vivo human normal and cancerous esophagus tissues with optical coherence tomography," Laser Physics Letters 8(1), 71-77 (2011).

28. S. Carvalho, N. Gueiral, E. Nogueira, R. Henrique, L. Oliveira, and V. V. Tuchin, "Glucose diffusion in colorectal mucosa - a comparative study between normal and cancer tissues," Journal of Biomedical Optics 22(9), 091506 (2017).

29. P. Schiebener, J. Straub, J. M. H. L. Sengers, and J. S. Gallagher, "Refractive index of water and steam as function of wavelength, temperature and density," Journal of Physical and Chemical Reference Data 19(3), 677-717 (1990).

30. A. N. Bashkatov, E. A. Genina, and V. V. Tuchin, "Measurement of glucose diffusion coefficients in human tissues," Chap. 19 in Handbook of Optical Sensing of Glucose in Biological Fluids and Tissues, V. V. Tuchin (Ed.), Taylor \& Francis Group LLC, CRC Press, 587-621 (2009).

31. V. D. Genin, D. K. Tuchina, A. J. Sadeq, E. A. Genina, V. V. Tuchin, and A. N. Bashkatov, "Ex vivo investigation of glycerol diffusion in skin tissue," Journal of Biomedical Photonics \& Engineering 2(1), 010303 (2016).

32. L. M. Oliveira, M. I. Carvalho, E. Nogueira, and V. V. Tuchin, "The characteristic time of glucose diffusion measured for muscle tissue at optical clearing," Laser Physics 23(7), 075606 (2013).

33. L. Oliveira, M. I. Carvalho, E. M. Nogueira, and V. V. Tuchin, "Diffusion characteristics of ethylene glycol in skeletal muscle," Journal of Biomedical Optics 20(5), 051019 (2015).

34. I. Carneiro, S. Carvalho, R. Henrique, R. M. Oliveira, and V. V. Tuchin, "A robust ex vivo method to evaluate the diffusion properties of agents in biological tissues," Journal of Biophotonics 12(4), e201800333 (2019).

35. A. Kotyk, K. Janacek, Membrane Transport: An Interdisciplinary Approach, Plenum Press, New York (1977). 
36. D. Zhu, J. Wang, Z. Zhi, X. Wen, and Q. Luo, "Imaging dermal blood flow through the intact rat skin with an optical clearing method," Journal of Biomedical Optics 15, 026008 (2010).

37. B. Choi, L. Tsu, E. Chen, T. S. Ishak, S. M. Iskandar, S. Chess, and J. S. Nelson, "Determination of chemical agent optical clearing potential using in vitro human skin," Lasers in Surgery and Medicine 36, 72-75 (2005).

38. D. K. Tuchina, V. D. Genin, A. N. Bashkatov, E. A. Genina, and V. V. Tuchin, "Optical clearing of skin tissue ex vivo with polyethylene glycol," Optics and Spectroscopy 120(1), 28-37 (2016).

39. A. N. Bashkatov, E. A. Genina, V. A. Grishaev, S. V. Kapralov, V. I. Kochubey, and V. V. Tuchin, "Study of the changes of gastric wall mucosa optical properties under the impact of aqueous solutions of haemoglobin and glucose for improving conditions of the laser coagulation," Journal of Biomedical Photonics \& Engineering 3(4), 040304 (2017).

40. S. Golovynskyi, I. Golovynska, L. I. Stepanova, O. I. Datsenko, L. Liu, J. Qu, and T. Y. Ohulchanskyy, “Optical windows for head tissues in near-infrared and short-wave infrared regions: approaching transcranial light applications," Journal of Biophotonics 11(12), e201800141 (2018). 